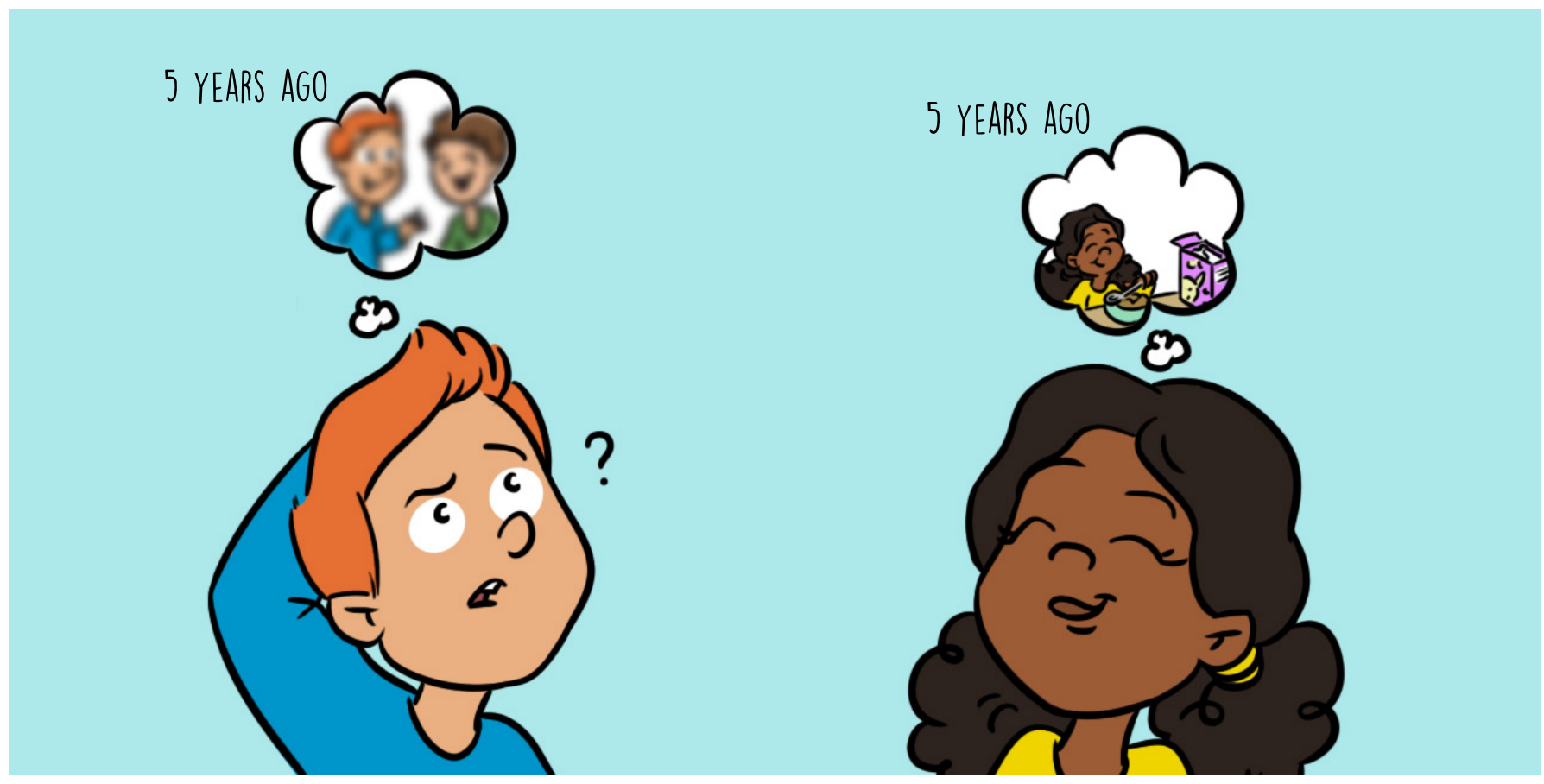

\title{
PEOPLE WHO RARELY FORGET
}

\section{Navid Reza Ghaffari* and James Lafayette McGaugh}

Department of Neurobiology and Behavior, Center for the Neurobiology of Learning and Memory, University of California, Irvine, Irvine, CA, United States

YOUNG REVIEWERS:

UC IRVINE BRAIN EXPLORER ACADEMY

AGES: 8-14
Imagine what you did yesterday. Most of us can easily go through the day in our minds and describe what happened. Now think about what you did 2 weeks ago. Unless something especially important or interesting happened, you probably remember very little. Zoom out one more time and try to remember what happened 1 month ago. Are you having trouble? Although it is easy to remember the past few days, it is harder to remember what happened more than 1 week ago. Now imagine that suddenly you can remember what you did after school exactly 1 month ago. Even better, you can remember what you did after school on specific days last year and the year before that! Impossible? Not for people who have Highly Superior Autobiographical Memory.

\section{INTRODUCTION}

There are many kinds of very strong memory. Some people can quickly memorize the order of an entire deck of cards. Others can remember detailed maps of large cities. One person can even draw an entire city 
in almost perfect detail after seeing it just once from a helicopter [1]. We recently discovered a new type of very strong memory: Highly Superior Autobiographical Memory.

\section{WHAT IS HIGHLY SUPERIOR AUTOBIOGRAPHICAL MEMORY?}

Highly Superior Autobiographical Memory, also known as HSAM, is just a fancy way of describing people who have a very good autobiographical memory. And by "autobiographical," we mean memory for anything related to ourselves. If you give individuals who have HSAM a random date from the past (for example: August 17, 2012), they can quickly say it was a Friday and then tell you some details about the day. What kinds of details? They could possibly tell you what they did that day, who they talked to, what the weather was like, and maybe even what they ate for lunch! What if you ask them details about when something happened, such as the last time they went to Disneyland? They can very likely tell you the exact date and day of the week.

\section{HOW WAS HSAM DISCOVERED?}

In 2000, a young woman named Jill Price contacted McGaugh to say that she had a memory problem. She said she had trouble forgetting things. This was very unusual! If a person says they have a memory problem, then it usually means they have trouble remembering things. After talking to her, it became very clear that she had an amazing memory. Her memory was then tested over the next few years. For one of the tests, she was asked to write down the date and what she was doing for the past 23 Easters. This was a very hard test, because Easter falls on a different date each year. She got all the dates correct except for one! What made this even more interesting was that Jill Price did not even celebrate Easter. A paper discussing Jill's memory was published in 2006 [2]. After that, more people contacted us to say that they also had HSAM. In December 2010, the TV show "60 Minutes" featured six people who have HSAM. Over 19 million people saw this TV show. Immediately afterwards, hundreds of viewers quickly contacted us and asked to have their memory tested! Currently, we have discovered fewer than 100 people who have HSAM.

\section{WHAT EXACTLY DO PEOPLE WITH HSAM REMEMBER?}

At the beginning of this article, we said that people with HSAM can remember details about what they did on almost every day of their lives. 
Although people with HSAM have memories of when they were children, they are much better at remembering experiences that happened after the age of 14. For most of their memories, they can tell you the date and day of the week when the experiences happened. Also, their memories are especially strong for anything of interest to them. For example, one person with HSAM really likes American football. His favorite team is the Pittsburgh Steelers. For every Steelers game, he can tell you the exact date, who they played, and the score!

\section{ARE PEOPLE WITH HSAM BETTER AT MEMORIZING THINGS?}

You already know that people with HSAM have a very strong autobiographical memory. Do you think people with HSAM are also better at memorizing things, like long lists of numbers or words? The answer is no. People with HSAM are no better than ordinary people at memorizing lists of things [3]. That is why this ability is called "Highly Superior Autobiographical Memory."

\section{DO PEOPLE WITH HSAM LEARN BETTER THAN ORDINARY PEOPLE OR FORGET INFORMATION MORE SLOWLY?}

To find out if people with HSAM learn better or forget information more slowly, ordinary and HSAM individuals were asked what they did 1 week ago, 1 month ago, 1 year ago, and 10 years ago. Ordinary people were just as good as HSAM subjects at telling us what they did during the past few days. This meant that people with HSAM do not learn more information than ordinary people. If people with HSAM did learn more information, then they would have been able to remember more details about their experiences in the past few days! We started to see differences between people with HSAM and ordinary people as we went further in the past (Figure 1). Ordinary people barely remembered any of their personal experiences after 1 month. On the other hand, people with HSAM remembered some details of what they did 1 month ago, 1 year ago, and 10 years ago! Therefore, people with HSAM do not have a stronger learning ability but rather a slower process of forgetting [4].

\section{ARE THE BRAINS OF PEOPLE WITH HSAM DIFFERENT?}

You may be wondering if people with HSAM have brains that are different than those of ordinary people. To try to answer this question, we used a special technique called magnetic resonance imaging (MRI). 
Figure 1

As time passes, look at what happens to the memory of people with HSAM vs. ordinary people. Can you spot the differences?
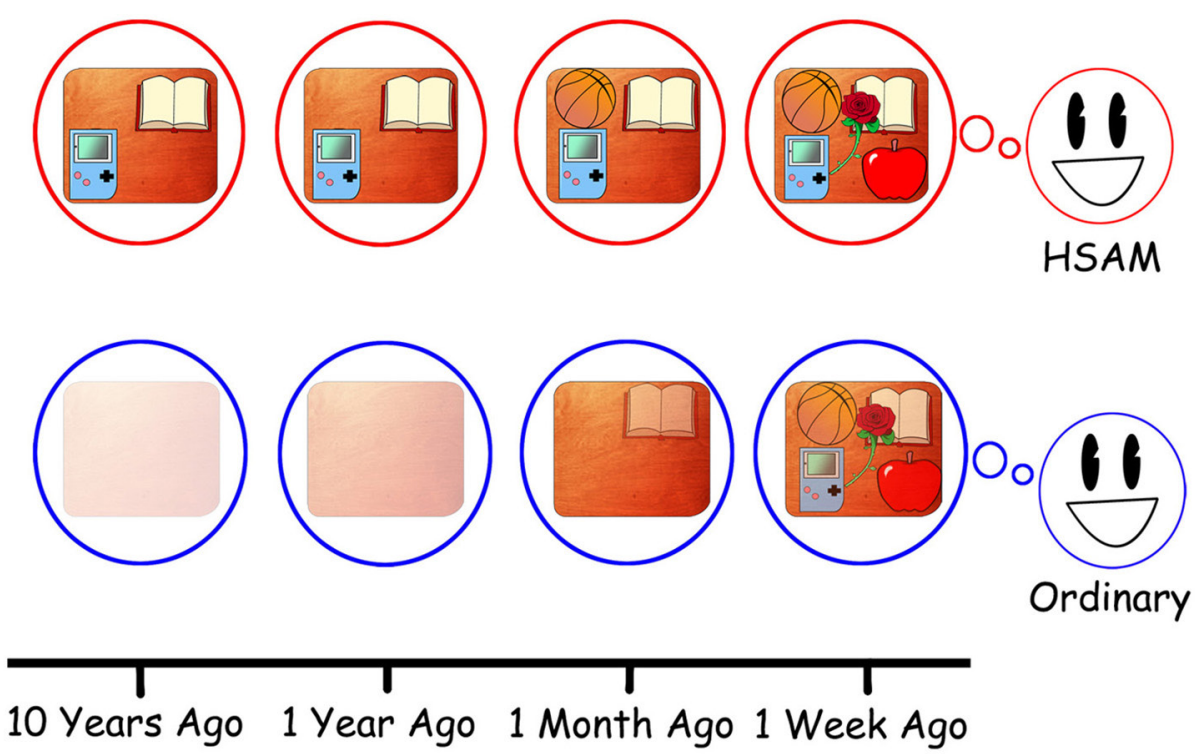

Figure 1

$\mathrm{MRI}$ is like a fancy camera that can take a picture of the brain. When scientists looked at the MRI images, they saw that some parts of the HSAM brain were different in both size and shape from the brains of ordinary people! Which parts were different? Brain areas called the inferior and middle temporal gyri, temporal pole, the anterior insula, and the parahippocampal gyrus. Do not worry; you do not have to remember these names! You can think about these brain areas as players on a team. They all work together to create our autobiographical memories [5].

We know that people with HSAM have brain areas that are different, but how about the connections between the brain areas? To look at the connections, we used another special imaging technique called diffusion tensor imaging (DTI). We discovered that one of the connections between brain areas, called the uncinate fasciculus, is bigger in people who have HSAM [5]. What does this mean? Imagine you and your school friends are on Island A. Across the water is Island B, with friends from another school. You want to talk to your friends on Island $\mathrm{B}$, but your phone is not working and they cannot hear you if you shout. Lucky for you, there is a bridge that connects the two islands. If the bridge is small, only a few people can cross at a time. If the bridge is big, then more people can easily cross and get to the other island. Think of the uncinate fasciculus as a bridge that connects brain areas. A bigger uncinate fasciculus allows brain areas to communicate easier and faster (Figure 2). 


\section{Figure 2}

You and eight other friends are on Island $\mathrm{A}$. You want to talk to your friends on Island B. If there is a small bridge, only three people can cross at a time. If there is a big bridge, six people can cross! The bigger the bridge, the more people can cross. Think of the islands as being brain areas, and the uncinate fasciculus as a bridge that connects them. Because people with HSAM have a bigger uncinate fasciculus, more information can be shared between brain areas.

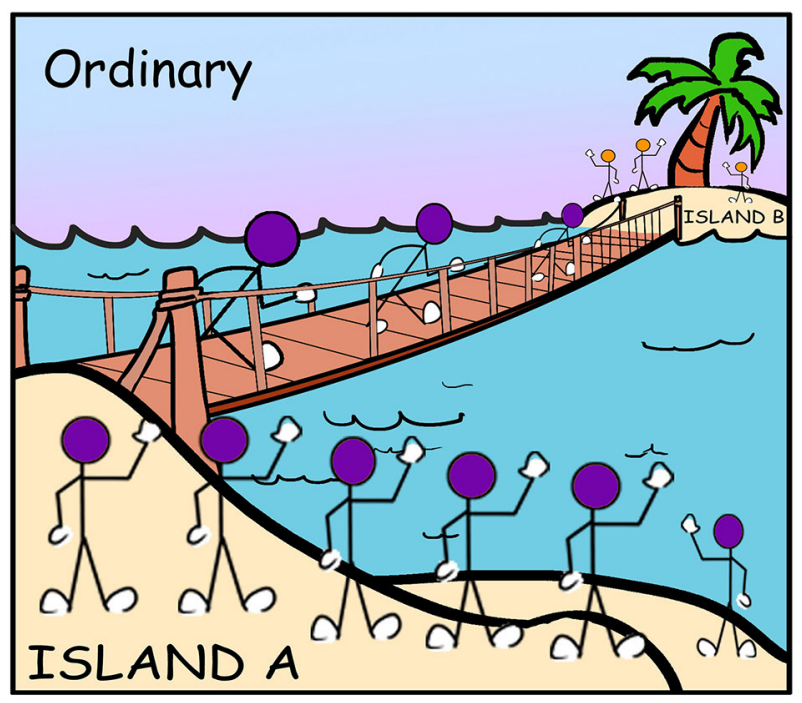

SMALL BRIDGE vS BIG BRIDGE

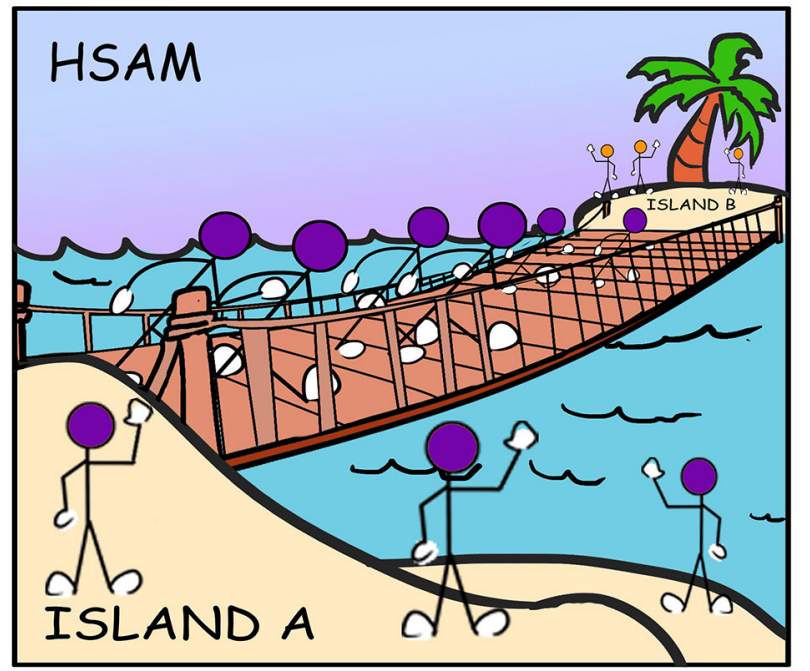

Figure 2

As you now know, people with HSAM have a very strong autobiographical memory. It is important to study people with HSAM because we can learn more about how memory works. If we understand how memory works, then we can use that information to help people who have problems with memory. Imagine a car that has stopped working. You want to fix it right away. If you do not know how a car works, then do you think you could fix it? Probably not! If you want to fix the car, then you must first understand how it works. Just like you would look at the engine to learn how a car works, we look at the brain to learn how memory works. We have learned a lot from studying HSAM, but there is much more we need to discover. The brain is a big mystery. Maybe people with HSAM will help us to solve that mystery. 


\section{REFERENCES}

1. McGaugh, J. L. 2017. Highly Superior Autobiographical Memory. Reference Module in Neuroscience and Biobehavioral Psychology. Learning and Memory: A Comprehensive Reference, 2nd Edn. Elsevier. 137-45.

2. Parker, E. S., Cahill, L., and McGaugh, J. L. 2006. A case of unusual autobiographical remembering. Neurocase 12:35-49. doi: 10.1080/13554790500473680

3. McGaugh, J. L, and LePort, A. K. 2014. Remembrance of all things past. Sci. Am. 310:40-5. doi: 10.1038/scientificamerican0214-40

4. LePort, A. K., Stark, S. M., McGaugh, J. L., and Stark, C. E. 2016. Highly superior autobiographical memory: quality and quantity of retention over time. Front. Psychol. 6:2017. doi: 10.3389/fpsyg.2015.02017

5. LePort, A. K, Mattfeld, A. T., Dickinson-Anson, H., Fallon, J. H., Stark, C. E., Kruggel, F., et al. 2012. Behavioral and neuroanatomical investigation of highly superior autobiographical memory (HSAM). Neurobiol. Learn. Mem. 98:78-92. doi: 10.1016/j.nlm.2012.05.002

SUBMITTED: 26 March 2018; ACCEPTED: 24 September 2018; PUBLISHED ONLINE: 24 October 2018.

EDITED BY: Michael A. Yassa, University of California, United States

CITATION: Ghaffari NR and McGaugh JL (2018) People Who Rarely Forget. Front. Young Minds 6:55. doi:10.3389/frym.2018.00055

CONFLICT OF INTEREST STATEMENT: The authors declare that the research was conducted in the absence of any commercial or financial relationships that could be construed as a potential conflict of interest.

COPYRIGHT @ 2018 Ghaffari and McGaugh. This is an open-access article distributed under the terms of the Creative Commons Attribution License (CC BY). The use, distribution or reproduction in other forums is permitted, provided the original author(s) and the copyright owner(s) are credited and that the original publication in this journal is cited, in accordance with accepted academic practice. No use, distribution or reproduction is permitted which does not comply with these terms.

\section{YOUNG REVIEWERS}

\section{UC IRVINE BRAIN EXPLORER ACADEMY, AGES: 8-14}

We are Brain Explorers from the University of California, Irvine Brain Explorer Academy! We spend our Saturday mornings learning about the brain from scientists at the Center for the Neurobiology of Learning and Memory. We love reading and reviewing Frontiers for Young Minds articles! 


\section{AUTHORS}

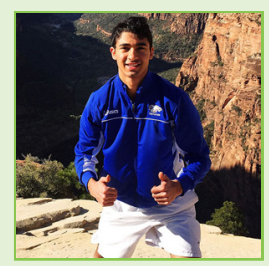

\section{NAVID REZA GHAFFARI}

I graduated from the University of California-Irvine in June 2018. I find the brain extremely fascinating and really enjoy learning about its structure and function. I am particularly interested in the neural circuitry of memories. Outside of research, I enjoy traveling, hiking, playing tennis, soccer, and the piano. *nrghaffa@uci.edu

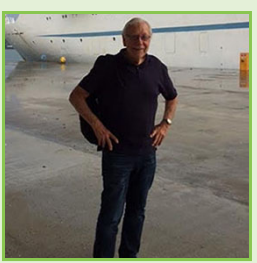

\section{JAMES LAFAYETTE MCGAUGH}

I am a professor of Neurobiology and Behavior at the University of California, Irvine. My research investigates the neural processes underlying the formation of memories. In my spare time, I play clarinet in a concert band and sax in jazz bands. I like to make furniture in my woodshop and do other construction projects. I also like to travel. 